\title{
Musik Iringan Hudoq Kita' sebagai Seni Pertunjukan Wisata di Desa Pampang Kota Samarinda
}

\author{
Hudoq Kita' Musical Accompaniment as Tourism Performance Art in Pampang Village, \\ Samarinda City
}

Meldi Didiawan Noor Tobing*, Program Studi Etnomusikologi, Fakultas Ilmu Budaya, Universitas Mulawarman. Email: adi.meldi.am@gmail.com

Asril Gunawan, Program Studi Etnomusikologi, Fakultas Ilmu Budaya, Universitas Mulawarman. Email: gunawanasril5@gmail.com

Aris Setyoko, Program Studi Etnomusikologi, Fakultas Ilmu Budaya, Universitas Mulawarman. Email: aris.setyoko@fib.unmul.ac.id

\author{
Received: \\ 9 Agustus 2021 \\ Accepted: \\ 15 September 2021 \\ Published: \\ 30 Oktober 2021
}

\section{Keywords:}

hudoq kita', art of tourism, dayak kenyah tribe, pampang village

\section{Kata kunci:}

hudoq kita', seni wisata, suku dayak kenyah, desa pampang

\begin{abstract}
:
Hudoq Kita' can be presented in two different forms of presentation. In addition to ritual music, the art form is also presented in the form of musical entertainment art of tourism. Hudoq Kita' entertainment music is generally displayed on every Sunday in Lamin Pemung Tawai Pampang village. This research uses qualitative methods, including observation, data collection, and data analysis. The technique in question is the observation of the research objects and the determination of informants. The data collection techniques include literature studies, interviews, and documentation. The last is the technique of data analysis by utilizing data that has been found in the field. The research results will explain with the facts of the finding in the field by the author. By the thesis title above, this research will describe the traditional Pelas Tahun, Hudoq Kita' and its accompaniment music with ritual context. The author will explain how Hudoq Kita' accompaniment music is turning into the entertainment of tourist art contextually and textually.
\end{abstract}

\begin{abstract}
Abstrak:
Hudoq Kita' dapat disajikan dalam dua bentuk penyajian yang berbeda. Adapun bentuk kesenian tersebut selain sebagai musik ritual juga disajikan dalam bentuk musik hiburan seni wisata. Musik hiburan Hudoq Kita' umumnya ditampilkan pada setiap hari minggu di lamin Pemung Tawai Desa Pampang. Penelitian ini menggunakan metode kualitatif meliputi observasi, pengumpulan data dan analisis data. Adapun Teknik yang dimaksud adalah observasi meliputi objek penelitian dan penentuan informan. Teknik pengumpulan data meliputi studi pustaka, wawancara, dan dokumentasi. Terakhir yakni teknik analisis data dengan memanfaatkan datadata yang telah ditemukan lapangan. Hasil penelitian akan menjelaskan dengan fakta temuan di lapangan oleh penulis. Sesuai dengan judul skripsi yang diatas, pada tulisan ini akan memaparkan tentang upacara adat Pelas tahun, Hudoq Kita' dan musik iringan Hudoq Kita' dengan konteks ritual. Adapun penulis akan menjelaskan bagaimana musik iringan Hudoq Kita' yang beralih ke sajian hiburan seni wisata secara kontekstual dan tekstual.
\end{abstract}

\section{Citation:}

Tobing, D. K. T., Gunawan, A., \& Setyoko, A. (2021). Musik Iringan Hudoq Kita' sebagai Seni Pertunjukan Wisata di Desa Pampang Kota Samarinda. Jurnal Mebang: Kajian Budaya Musik dan Pendidikan Musik, 2(1), 51-62. https://doi.org/10.30872/mebang.v1i2.14 


\section{Pendahuluan}

Hudoq Kita' sebenarnya adalah upacara adat istiadat yang bersifat sakral dalam kepercayaan suku Dayak Kenyah. Prinsipnya sama dengan tari Hudoq dari Dayak Bahau dan Modang, yakni upacara menyambut tahun tanaman maupun menyampaikan rasa terima kasih pada dewa yang telah memberikan hasil panen yang baik (Sili et al., 2019) . Hudoq Kita' diselenggarakan bersamaan dengan upacara adat Pelas Tahun (upacara menanam padi dan menuai padi). Ritual upacara adat ini merupakan ungkapan rasa syukur pada Tuhan dan para roh leluhur masyarakat suku Dayak Kenyah, agar pada masa panen yang akan datang diberikan hasil yang lebih baik (Wulandari, 2018) .

Pelaksanaan Hudoq Kita' juga tidak lepas dari peranan musik yang merupakan syarat ketika ritual adat berlangsung. Kesenian tradisi musik dan tari pada upacara ritual, merupakan peristiwa budaya yang praktiknya sering dijumpai dalam kehidupan masyarakat tradisi (Gunawan, 2021). Artinya, musik yang dihadirkan dalam upacara ritual menjadi satu kesatuan yang tidak dapat dipisahkan dalam setiap prosesinya. Upacara ritual dan musik tersebut masih dapat ditemukan dimasyarakat sebagai suatu warisan dari leluhur masyarakat Dayak Kenyah dan bersifat khusus, yang menimbulkan rasa hormat kepada leluhur (Hadi, 2006:31). Pada jaman dahulu, alat musik yang digunakan untuk mengiringi ritual Hudoq Kita' adalah jatung dan gong. Menurut kepercayaan suku Dayak Kenyah, bahwa ketika kedua alat musik tersebut dimainkan dapat mengundang dewi padi dan roh leluhur turun ke bumi untuk turut serta melangsungkan ritual Hudoq Kita'.

Berdasarkan pengamatan penulis di lapangan, menunjukkan bahwa kesenian musik Hudoq Kita' dapat disajikan dalam dua bentuk penyajian yang berbeda. Adapun bentuk kesenian tersebut selain sebagai musik ritual juga disajikan dalam bentuk musik hiburan seni wisata. Musik hiburan Hudoq Kita' umumnya ditampilkan pada setiap hari minggu di lamin Pemung Tawai Desa Pampang. Namun, penyajian musik untuk ritualnya disajikan dalam upacara adat Pelas. Oleh karena itu, kedua bentuk musik tersebut menjadi daya tarik tersendiri bagi penulis dalam mengamati khususnya musik iringan Hudoq Kita' dilihat dalam perspektif seni wisata. Disisi lain, meskipun penyajiannya berbeda namun, kesenian tersebut mampu berjalan beringingan dan tidak mendominasi satu sama lain. Hal tersebut menunjukkan bagaimana kesenian mampu disesuaikan berdasarkan kontekstualnya.

\section{Metode}

Penelitian ini menggunakan metode kualitatif, proses pengambilan data di lapangan dilakukan untuk menjawab permasalahan dalam penelitian ini. Data yang didapatkan lalu dideskripsikan dan dianalisis dengan menggunakan konsep penelitian kualitatif. Selama penetian lapangan berlangsung, berbagai pekerjaan dilakukan untuk mencari data dan mengelolahnya ke dalam tulisan diantaranya: observasi penelitian, teknik mengumpulkan data dan analisis data. Observasi penelitian terhadap objek dilakukan mengetahui permasalahan yang akan diteliti di Desa Budaya Pampang. Setelah itu, selain itu penulis juga menentukan informan dan melakukan wawancara pada masyarakat, tokoh adat dan seniman untuk mendapatakan. Adapun metode lain yang dilakukan yaitu studi kepustakaan, wawancara dan dokumentasi. 


\section{Hasil dan pembahasan}

Suku Dayak Kenyah di Kalimantan Timur masih sangat menjaga adat istiadat maupun kepercayaan terhadap roh leluhur yakni para dewa. Hal ini tersebut dapat di buktikan pada Hudoq Kita' yang hingga saat ini masih dipertahankan dan merupakan peninggalan yang harus dijalankan pada waktu ritual pelas tahun. Hudoq Kita' adalah simbol permohonan yang dilakukan melalui gerakan tari yang melawai dengan melangkah dan menghentak disertai dengan iringan musik yang syarat akan makna ritualnya. Menurut (Sili et al., 2019) Hudoq Kita' merupakan permohonan dan persembahan kepada roh-roh leluhur dan dewi padi, yang dipercayai dapat membantu kesuburan, keselamatan, dan kesejahteraan suku Dayak Kenyah. Adapun pelaksanaan Hudoq Kita' pada jaman dahulu dibawakan oleh 12 orang penari wanita berusia antara 40-60 tahun, ditarikan oleh kaum wanita dewasa (Indrahastuti, 2016).

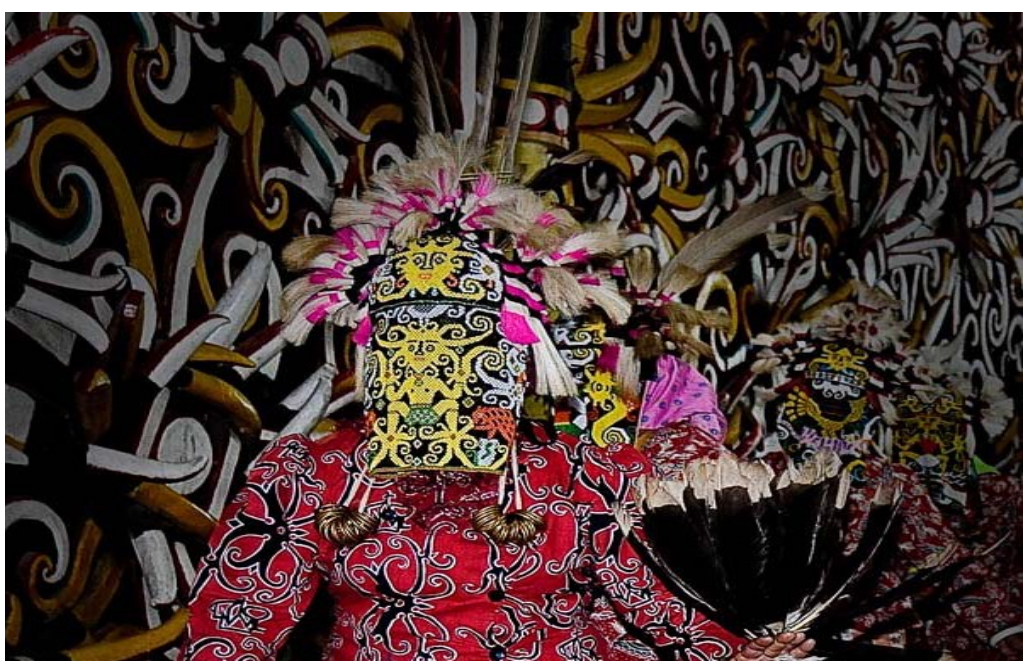

\section{Gambar 1. Kancet Hudoq Kita'}

Hubungan upacara Hudoq Kita' hingga saat ini saling terkait erat dengan kesenian tradisi khususnya musik dan tari. Hal tersebut dapat ditandai dimana kesenian meliputi: tari dan musik selalu dihadirkan disetiap ritual, khususnya upacara Hudoq Kita'. Adapun setiap keterlibatan pendukung penari dan pengiring musik biasanya tidak mendapatkan imbalan khusus, karena diadakannya ritual tersebut tidak lain sebagai kebutuhan bersama (Indrahastuti, 2016). Hal itu sekaligus menunjukkan bahwa masyarakat Dayak Kenyah memiliki kesadaran serta rasa tanggung jawab sosial dalam setiap kegiatan ritual Hudoq Kita'. Pada masa pesta panen, ritual Hudoq Kita' memiliki makna yang dapat disimbolkan sebagai simbol kekuatan roh, baik itu simbol kekuatan jahat maupun simbol kebaikan. Suku Dayak Kenyah di desa Pampang topeng dianggap sebagai sosok dewa-dewi padi, dan diyakini sebagai simbol kebaikan bagi masyarakat. Adapun topeng Hudoq yang digunakan terbuat dari anyaman manik dan bermotif menyerupai binatang yang disakralkan. 


\subsection{Pelaksanaan Upacara Pelas Tahun}

Pelas Tahun merupakan salah satu upacara ritual suku Dayak Kenyah di desa Pampang. Pelaksanaan upacara ritual adat Pelas Tahun diadakan setiap tahunnya oleh masyarakat suku Dayak Kenyah bertepatan dengan masa awal menanam padi hingga pesta panen. Tujuan dilaksanakanya upacara ritual adat Pelas tahun merupakan ungkapan rasa syukur atas hasil panen ladang yang berlimpah dan terhindar dari hama maupun bencana pada masa saat masuknya musim tanam berikutnya.

Upacara adat Pelas tahun yang ada sejak jaman nenek moyang dahulu kala, hingga kini tetap dilestarikan dan dilangsungkan oleh suku Dayak Kenyah yang di Desa Budaya Pampang. Adapun alasan masih dilangsungkan upacara adat Pelas tahun karena,sebagian masyarakat suku Dayak Kenyah masih bergantung dengan hasil panen dari berladang. Disamping itu, pelaksanaan upacara adat Pelas Tahun saat ini telah mendapatkan dukungan dan menjadi salah satu agenda tahunan Dinas Pariswisata Kota Samarinda. Hasil wawancara dilapangan bersama Ketua Kesenian Desa Pampang juga menjelaskan bahwa "Dulu pelas tahun ini, diadakan oleh warga-warga Dayak Kenyah pampang saja. Setelah jadi destinasi wisata pelaksaan acara atau ritual adat termasuk pelas tahun mendapat bantuan dana dan fasilitas dari Dinas Pariwisata Kota Samarinda."

Berdasarkan kutipan di atas, menegaskan pelaksanaan upacara adat Pelas Tahun di desa Pampang tidak hanya untuk kebutuhan upacara ritual adat, melainkan juga terbuka bagi wisatawan asing maupun lokal yang ingin menyaksikan upacara adat Pelas tahun. Pelaksaan upacara Pelas Tahun juga mendapat dukungan dari Dinas Pariwisata Kota Samarinda, dalam hal bantuan dana dan fasilitas yang akan menunjang selama upacara ritual adat berlangsung.

Hudoq Kita' merupakan syarat dan sarana ritual setiap pelaksanaan Upacara Pelas Tahun. Menurut kepercayaan suku Dayak Kenyah, Hudoq Kita' adalah sebuah tiruan dewa dewi padi yang turun ke bumi untuk ikut serta ketika upacara Pelas tahun berlangsung. Oleh karena itu, upacara pelas tahun dan Hudoq Kita' adalah satu kesatuan yang tidak dapat dipisahkan dan disakralkan. Hal itu menunjukkan bagaimana peran dan fungsinya masih terjaga dengan baik.

\subsection{Prosesi Upacara Pelas Tahun}

Pada saat upacara Pelas Tahun berlangsung, adapun tahapan disetiap prosesinya yaitu 2 jenis persembahan tarian utama sebagai berikut:

\subsubsection{Kancet Lamimpa}

Tari Lemimpa atau Kancet Lemimpa adalah sebuah tari yang dibawakan oleh beberapa wanita suku Dayak Kenyah, tarian tersebut dibawakan diawal prosesi upacara Pelas Tahun. Pada tarian Lemimpa, penari dan pemangku adat menggunakan media air dalam prosesi Lemimpa. Air yang sudah melalui prosesi doa atau mantra oleh pemangku adat, lalu disiramkan pada tanaman padi yang mulai tumbuh di ladang. Tujuan dalam prosesi Lemimpa adalah memohon berkat kepada Tuhan dan dewi padi untuk kesuburan pada masa tanam. Data mengenai prosesi Lemimpa. 


\subsubsection{Hudoq Kita'}

Hudoq Kita' atau kancet Udo' Aban merupakan prosesi kedua setelah prosesi Lemimpa. Hudoq Kita' adalah tarian menggunakan topeng dari manik tiruan dari roh leluhur dan dewa dewi padi suku Dayak kenyah, tujuan di bawakanya Hudoq Kita' pada upacara Pelas tahun adalah untuk mengusir hama penggangu tanaman, roh jahat dan bencana alam agar tanaman padi tumbuh subur. Adapun hal tujuan lainya dari Hudoq Kita', yaitu untuk hasil panen yang lebih baik dan bermanfaat untuk dinikmati. Tujuan utama diadakanya prosesi upacara Pelas tahun adalah, untuk melestarikan adat dari nenek moyang yang hingga sekarang masih dilaksanankan. Pada upacara ini juga menjadi edukasi dan sosialisasi antar masyarakat suku Dayak Kenyah di desa Pampang, dan wisatawan yang berkunjung untuk menyaksikan upacara Pelas Tahun, sekaligus hiburan berlangsung.

\subsection{Waktu dan Tempat Pelaksanaan}

Awal diselenggarakan upacara ritual Pelas Tahun dimulai sejak tahun 1999 di bulan Juni. Agenda ini rutin dilaksanakan setiap tahunya oleh suku Dayak Kenyah Desa Pampang, dan Dinas Pariwisata Kota Samarinda. Pelaksanaan upacara Pelas Tahun bertempat di lapangan Lamin Adat Pemung Tawai, Jl.Wisata Budaya Pampang, No.32, RT.03, Kelurahan Budaya Pampang, Kelurahan Sungai Siring, Kecamatan Samarinda Utara, Kota Samarinda, Kalimantan Timur 75119. Waktu pelaksaan dimulai biasanya di pagi hari pukul 09.00 WITA hingga selesai. Pada saat upacara dimulai, tidak hanya masyarakat desa Pampang saja yang boleh hadir pada saat upacara adat ritual Pelas tahun berlangsung, namun masyarakat luar desa Pampang atau wisatawan, diizinkan melihat upacara ritual Pelas Tahun disetiap prosesinya. Selain menyaksikan prosesi ritual, wisatawan dapat menyaksikan hiburan seni musik dan tari, yang di tampilkan oleh seniman Dayak Kenyah desa Pampang.

\subsection{Musik Iringan Hudoq Kita'}

Pelaksaan Hudoq Kita' dalam prosesi upacara Pelas tahun, tidak terlepas dari iringan musiknya yang menjadi syarat selama prosesi berlangsung. Pada setiap upacara adat, dalam hal penyajian musik ritual, suku Dayak Kenyah sampai sekarang masih memainkan disetiap ritual khususnya pada upacara adat pelas di desa Pampang. Peresmian desa Pampang sebagai desa wisata oleh Pemerintah Kota Samarinda, tidak menjadi halangan untuk masyarakat desa Pampang dalam menjalankan kegiatan budaya dalam konteks ritual. Adapun penulis akan mendeskripsikan musik Iringan Hudoq Kita' sesuai prespektif teori yang akan di gunakan sebagai berikut:

\subsubsection{Instrumental}

Pada setiap penyajian musik tentunya instrument menjadi media dalam menghasilkan bunyi yang disusun hingga menjadi sajian musik yang layak didengar. Hal ini juga perjelas oleh Alan P. Merriam (1964), bahwa peran instrument sangat lah penting dalam penyajian musik. Instrument juga menjadi alat bagi musisi untuk menciptakan music. berdasarkan musik pada iringan Hudoq Kita', dalam upacara Pelas juga menggunakan instrument dalam prosesi ritualnya. Instrument yang digunakan dalam mengiringi upacara Pelas Tahun menggunakan 
Jatung Utang. Instrument Jatung Hutang merupakan alat music dalam mengiringi Hudoq Kita'. Jatung Utang dimainkan dengan posisi pemain berdiri memukul bilah kayu bernada skala Pentatonik.

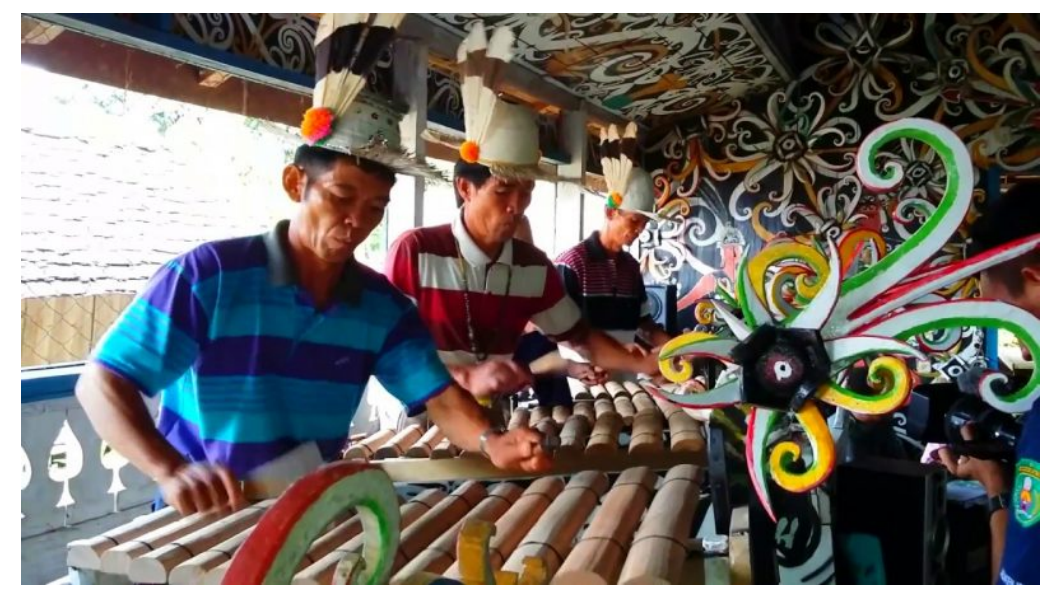

\section{Gambar 2. Instrumen Jatung Utang}

\subsubsection{Peran Musisi}

Melalui musik, musisi mengaktualisasikan potensi dirinya dalam mengungkapkan perasaan melalui nada-nada. Peran musisi menjadi sangat penting dalam sebuah penyajian musik. Hal ini juga dikemukan oleh Alan P. Merriam (1964) peran status musisi sangatlah berpengaruh pada sajian musik, hal ini dapat dilihat dari cara musisi menuangkan ide ide yang kreatif dan edukatif dalam membuat sebuah bunyi menjadi sebuah karya musik. Musik Hudoq Kita' tidak lepas dari peran musisi yang jadi pendukung ketika mengiringi Hudoq Kita'. Setiap musisi masing-masing memiliki peran dalam permainan musik Hudoq Kita'. Pada permainan Jatung Hutang, terdapat 3 sampai 4 musisi yang memainkan alat musik tersebut. Dari berberapa pemain masing-masing memainkan pola berbeda hingga menjadi harmoni dan menjadi sebuah sajian musik untuk mengiringi jalanya upacara ritual.

\subsubsection{Fungsi Musik dalam Aspek Kebudayaan}

Musik Jatung Utang digunakan sebagai pengiring pada upacara-upacara upacara adat, untuk memperkuat kesan mistis. Semua perlengkapan dan tingkah laku dalam upacara, seperti menyanyikan atau membacakan mantra, menari, memainkan musik, termasuk sesaji dan properti yang dikenakan pamaliatan dipercaya mempunyai kekuatan gaib. Kekuatan itu dapat dimanfaatkan untuk melindungi dirinya dari gangguan makhluk halus dan dipercaya oleh masyarakat Dayak dapat mendatangkan roh halus yang dipanggil. Hal ini karena kekuatan gaib tersebut tidak hanya terdapat atau bersemayam dalam perilaku upacara saja, namun melekat pula pada semua bahan atau properti yang digunakan dalam upacara. Antara instrumen, jimat, dan properti lainnya dalam suatu upacara ritual merupakan satu kesatuan sakral yang penggunaannya tidak dapat dipisahkan antara satu dengan lainnya.

\subsection{Musik Hudoq Kita' dalam Seni Wisata}


Sejak resmi menjadi objek pariwisata di Kota Samarinda, tentunya Desa Budaya Pampang memiliki dampak negatif dan dampak positif. Tradisi adat tidak sepenuhnya dijalankan namun sebagian telah beralih untuk kebutuhan pariwisata. Tradisi kesenian budaya, yang selama ini merupakan simbolik bagi masyarakat Kenyah. Pertunjukan yang ditampilkan merupakan formalitas untuk kebutuhan pariwisata. Hal ini juga berkaitan dengan perubahan kesenian Hudoq Kita' yang terdapat pada iringan musiknya. Musik iringan Hudoq Kita' dalam konteks seni wisata terdapat perbedaan dengan konteks ritual, dalam hal ini hasil temuan di lapangan akan dijelaskan dan dikorelasikan menggunakan teori seni wisata dari RM.Soedarsono.

\subsubsection{Tiruan dari Aslinya dan Mini Atau Dikemas Singkat dan Padat}

Pada teori seni wisata yang dikemukan oleh R.M. Sudarsono (1999) bahwa dalam sebuah pertunjukan seni wisata merupakan tiruan asli dari budaya leluhur namun di kemas singkat dan padat, tetapi tidak meninggalkan nilai - nilai budaya yang menjadi salah satu ciri khas. Hudoq Kita' yang ditampilkan di Pampang, dari tampilan pertunjukan sangat mendekati cici teori tersebut, meliputi musik, tari dan aksesoris.

\subsubsection{Ditinggalkan Nilai-Nilai Sakral, Magis, dan Simbolis}

Pada pertunjukan hiburan seni wisata nilai - nilai sakral, magis dan simbolis selalu ditinggalkan karna berdasarkan konteksnya tidak kearah upacara adat. R.M. Sudarsono (1999) dalam teori seni wisata juga menjelaskan, bahwa ciri ciri pertunjukan seni wisata tidak lagi melibatkan hal yang berhubungan dengan nilai nilai sakral, magis dan simbolis. Ciri - ciri tersebut juga terdapat pada pertunjukan seni wisata Hudoq Kita', dalam pertunjukannya juga meninggal nilai yang di anggap sakral, magis dan simbolis, karena mengingat konteksnya bukanlah upacara adat melainkan hiburan.

\subsubsection{Penuh Variasi}

Iringan musik juga menjadi salah satu aspek yang harus dimainkan lebih variatif, tujuanya agar sajian musik menjadi lebih menarik dalam hal aransemen. Pada penampilan yang diharuskan singkat dan padat, tentunya seniman harus serius dalam hal managemen waktu dan penampilan yang maksimal. R.M. Sudarsono (1999) dalam teorinya menegaskan bahwa, pertunjukan seni wisata sangat terikat dengan durasi waktu singkat dan padat. Seniman dalam hal ini diharuskan memaksimalkan penampilanya. Pertunjukan musik Hudoq Kita' dalam kemasan seni wisata, terlihat dari aspek musiknya lebih variatif ketimbang musik iringan upacara.

\subsubsection{Murah Harganya}

Pelaksanaan acara seni wisata tidak mengeluarkan biaya yang begitu besar ,karena dalam pelaksanaan pertunjukan pariwisata tidak menggunakan syarat adat upacara dan durasi waktu yang panjang. Teori seni wisata oleh R.M. Sudarsono (1999) juga menjelaskan bahwa, pagelaran pertunjukan seni wisata tidaklah semahal biaya pagelaran upacara adat, karena tidak menggunakan syarat adat tertentu dan durasi waktu yang singkat. Pagelaran Hudoq Kita' 
dalam seni wisata tidak menggunakan syarat adat upacara dan durasi waktu yang Panjang, dalam pelaksanaanya juga tidak membutuhkan banyak biaya seperti upacara adat Pelas Tahun.

Pertunjukan Hudoq Kita' sebagai seni wisata di desa Pampang, berbeda dengan sajian ritual, perbedaan terletak pada iringan Hudoq diringi dengan instrumen Jatung yang dipentaskan sehari semalam disesuaikan kebutuhan dalam upacara Hudoq, sedangkan iringan musik Hudoq Kita' dalam seni wisata dimainkan dalam waktu kurang lebih 10 menit dan adanya penambahan instrumen Sampek yang dimainkan oleh tiga orang dan 1 orang memainkan tuvung. Dalam kemasan wisata, unsur-unsur ritual dalam iringan musik Hudoq Kita' seperti adanya pawang, sesajen dan mantra pemanggilan roh telah dihilangkan. Adapun terdapat pada kostum penari yang dikenakan. Penari Hudoq dalam kemasan wisata mengenakan baju lengan panjang, sarung dan penutup wajah sejenis cadar yang dihiasi manik-manik. Penari Hudoq dalam upacara ritual mengenakan kostum dari kulit pohon dan rumbai daun - daun.

Iringan musik Hudoq Kita' dalam konteks wisata dibawakan dan dikemas lebih variatif dibandingkan pada iringan upacara ritual, perpaduan tiga instrumen Sampek terdapat perbedaan yang membentuk harmoni pada masing-masing pemain Sampek. Pemain Sampek satu sebagai melodi, pemain Sampek dua sebagai harmoni dari nada sampek satu, pemain Sampek ketiga sebagai pengiring. Pengemasan musik Sampek sebagai kemasan wisata yang menarik dilakukan oleh Dewan Kesenian Budaya Pampang.

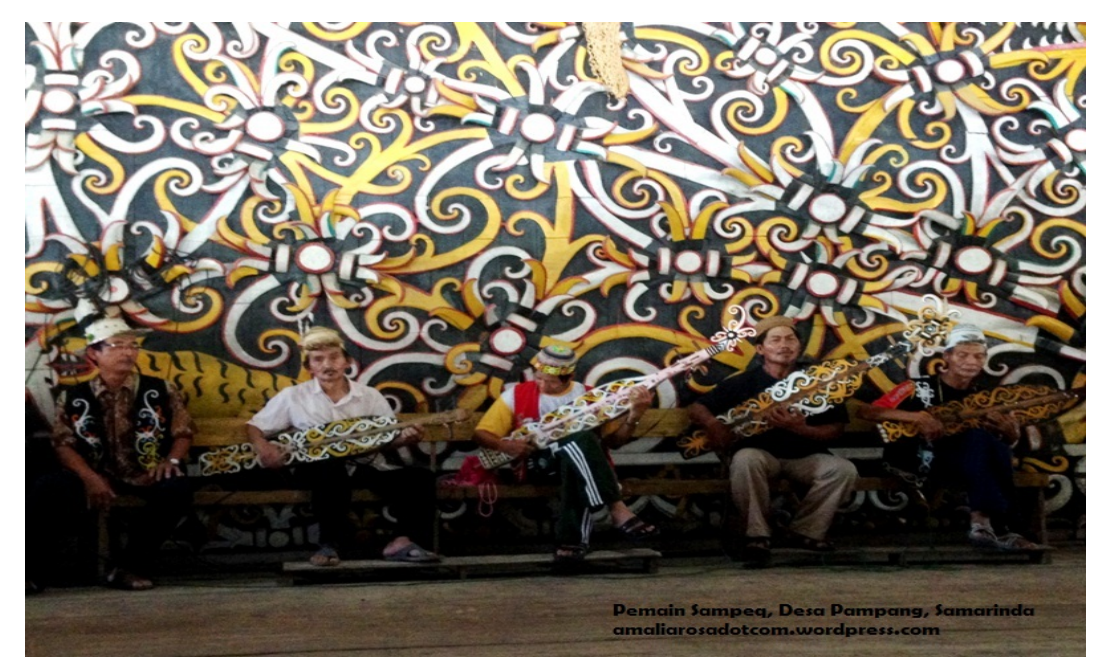

Gambar 3. Pemusik Sampeq

\subsection{Analisis Hudoq Kita' dalam Seni Wisata}

Hudoq Kita' yang digunakan dalam konteks pertunjukan wisata, tidak terlepas dari keterlibatan para masyarakat pendukungnya khususnya pelaku seni yang terlibat secara langsung. Keterlibatan setiap anggota masayrakat maupun pelaku seni memiliki peran dan fungsinya masing-masing. Hal itu sebagai bentuk jalinan sosial yang didalamnya terdapat perilaku kolektif. Artinya sebuah pertunjukan seni terlebih kebutuhan pertunjukan wisata sangat diperlukan kerja kolektif yang saling mendukung satu sama lain. Sehingga, pengujung 
yang datang menyaksikan kegiatan pertunjukan seni wisata, dapat merasakan suasana yang nyaman sebagaimana konsep pelayanan publik.

Berdasarkan hal tersebut, maka pertunjukan seni wisata khususnya bagi pelaku seni dalam musik Hudoq Kita' sangat perlu mempertimbangkan aspek penyajiannya. Hal itu berhubungan dengan daya artistik yang dapat memberikan pengaruh senang bagi pengunjung wisata. Memberikan daya tarik yang estetis dan nyaman bagi pengunjung wisata tentu tidaklah gampang. Semua perlu dilakukan persiapan yang matang baik dari persiapan hingga pertunjukannya. Hal terpenting dalam persiapan ini adalah kebutuhan akan sound sistem maupun kesiapan instrumen yang digunakan. Disamping itu, hal yang tidak dapat dipungkiri adalah faktor cuaca alam pastinya juga menjadi penentu terhadap kelancaran pertunjukan musik Hudoq Kita'. Artinya dengan adanya kesiapan yang matang maka akan memberikan kelancaran pada pertunjukannya musik Hudoq Kita'.

Sebagaimana penjelasan kontekstual di atas, aspek musikal musik Hudoq Kita' juga penting diamati dalam proses analisis musik. Menganalisis musik berarti menguraikan komponen-komponen pembentuk musik tersebut. Komponen dapat juga diartikan sebagai unsur pembentuk musik (Karyawanto, 2018). Pembahasan terkait aspek musikal diperlukan pemahaman dimana musik tidak lagi dipandang secara kontekstual melainkan ia diamati pada tekstualnya. Adapun pengertian tekstual adalah musik dipandang lebih pada kebutuhan musik itu sendiri. Misal, analisis musik dalam pendektan menurut Malm (1977), yang menyatakan terdapat tujuh indikator dalam mendeskripsikan musik (melodi) yaitu; (1) nada dasar, (2) wilayah nada, (3) jumlah nada, (4) jumlah interval, (5) Pola Kadensa, (6) Formula Melodi, dan (7) Kontur. Selain pendapat di atas disebutkan juga bahwa unsur-unsur musik meliputi: melodi, ritme, harmoni, dan timbre (warna bunyi) (Aaron Copland, 2009). Berdasarkan indikator analisis musik tersebut kemudian akan digunakan untuk menganalisis musik Hudoq Kita' dengan disesuaikan pada karakteristik musikalnya. Analisis juga dilakukan dengan menggunakan proses transkrip notasi terhadap melodi dan ritme musik Hudoq Kita'. Mentranskripsikan unsur-unsur musik pada dasarnya adalah mengalihkan unsur-unsur (Karyawanto, 2018). Adapun penjelasan analisis musik Hudoq Kita'dapat dijelaskan sebagai berikut.

\subsection{Nada Dasar (Pitch Center)}

Berdasarkan temuan dilapangan musik Hudoq Kita' menggunakan instrumen Sampek Kenyah dimana penggunaan tangga nadanya dapat disesusaikan pada kebutuhan pertunjukannya. Hasil analisis, ditemukan nada dasar Sampek dimainkan dengan menggunakan nada dasar E Major (4\#). Nada Dasar E Major dapat disusun dengan berdasarkan pada tingkatan nadanya dari nada rendah ke nada tinggi yang tersusun secara oktaf sehingga menjadi tangga nada utuh. Tangga nada merupakan kumpulan nada-nada dalam satu oktaf nada (delapan nada) yang terdiri dari dari beberapa interval dan membentuk musik (Nainggolan, 2019), disamping itu perlu juga diketahui bahwa secara karakteristik tangga nada Sampek juga dimainkan dalam skala tangga nada Pentatonik yang terdiri dari lima nada yaitu; $\mathrm{E}-\mathrm{F} \#-\mathrm{G} \#-\mathrm{B}-\mathrm{C} \#$.

\subsubsection{Wilayah Nada}


Wilayah nada dalam hal ini dapat dijelaskan berdasarkan gaya permainan melodi dari setiap instrument Sampek. Melodi instrument Sampek umumnya dapat dikondisikan sesuai kebutuhan sipemain, sehingga wilayah nada juga menyesuaikan pada jumlah oktaf instrument Sampek. Berdasarkan wilayah nada pada lagu Musik Hudoq Kita' dikondisikan dari setiap gaya permainan melodi masing-masing Sampek. Maksud dari hal tersebut bahwa permainan melodi dimainkan dengan menggunakan 3 instrumen Sampek yang masing-masing memiliki peran yang berbeda-beda. Permaian melodi Sampek I, dapat dimainkan hingga dua oktaf sehingga jangkauan wilayah nadanya dapat lebih luas dan Variatif. Sampek II, dimainkan dengan memainkan wilayah nada pada oktaf tengah dari Oktaf 1 da 2 (middle oktaf) berfungsi sebagai pembawa harmoni dari instrument Sampek. Sampek III, dimainkan hanya menggunakan wilayah nada 1 oktaf yang berfungsi sebagai ritem melodis. Disisi lain irama ritem juga diperkuat dengan adanya tambahan intrumen perkusi yakni Tuvung. Adapun transkrip tuvung sebagai berikut.

\subsubsection{Jumlah Nada}

Permainan melodi Musik Hudoq Kita' jika dianalisis berdasarkan hasil transkrip, maka diketahui jumlah nadanya hanya terdiri dari beberapa nada yang umumnya itu dimainkan secara berulang-ulang. Adapun jumlah nada yang terdapat dalam permainan melodi Sampek secara keseluruhan terdiri dari nada; E - F\# - G\# - B - C\# .

\section{Simpulan}

Pada era globalisasi fungsi musik tradisi bergeser salah satunya untuk kebutuhan hiburan seni wisata. Peristiwa ini sama halnya dengan iringan musik Hudoq Kita', dimana musik tradisi untuk kebutuhan upacara telah beralih ke hiburan seni wisata. Hal tersebut juga dijelaskan oleh RM. Soedarsono (1999) bahwa pertunjukan seni wisata dapat dilihat ciri - cirinya sebagai berikut: (1) tiruan dari aslinya, (2) bentuk mini atau dikemas singkat dan padat, (3) ditingkalkan nilai-nilai sakral, magis dan simbolisnya, (4) penuh variasi, (5) murah harganya. Pemaparan teori tersebut membuktikan bagaimana relasi musik ritual Hudoq Kita' telah beralih dari ritual menjadi seni wisata. Hudoq Kita' dalam konteks pertunjukan wisata, tidak terlepas dari keterlibatan masyarakat Pampang khususnya para seni yang terlibat dalam pertunjukan. Keterlibatan seniman, secara tidak langsung menjadi bentuk jalinan sosial dalam hal perilaku kolektif. Artinya sebuah pertunjukan wisata sangat diperlukan kerja kolektif dan mendukung satu sama lain. Dampak hal tersebut membuat pengujung yang datang menyaksikan kegiatan pertunjukan seni wisata, dapat merasakan suasana yang nyaman sebagaimana konsep pelayanan Tempat desa wisata semestinya.

\section{Referensi}

Copland, A. (2009). What to Listen for in Music. First New American Library.

Fajriansyah, A. A., Vivian, Y. I., \& Pratama, Z. W. (2021). Fungsi Daak Maraa' dalam Upacara Hudo' Kawit pada Masyarakat Suku Dayak Bahau di Kota Samarinda. Jurnal Mebang: Kajian Budaya Musik Dan Pendidikan Musik, 1(1), 14-24. https://doi.org/10.30872/mebang.v1i1.2 
Gunawan, A., Mursalim, M., \& Fahrurazi, F. (2019). Transformasi Musik Tingkilan dalam Kontinuitas di Era Globalisasi (Sebuah Pendekatan Etnomusikologis ). Prosiding Seminar Nasional Bahasa, Sastra, dan Seni (Sesanti) 2019, 1-16. http://eprosiding.fib-unmul.id/index.php/sesanti/article/view/3

Gunawan, A. (2021). Makna Simbolik Musik Daak Maraaq dan Daak Hudoq dalam Upacara Hudoq Bahau di Samarinda Kalimantan Timur. Resital: Jurnal Seni Pertunjukan, 21(2), 113-126. https://journal.isi.ac.id/index.php/resital/article/view/4462

Heriyawati, Y. (2016). Seni Pertunjukan dan Ritual. Yogyakarta: Ombak.

Indrahastuti, T. (2016). Kajian Semiotika pada Pertunjukan Hudoq Kita' di Desa Pampang Kalimantan Timur. https://repository.unmul.ac.id/assets/upload/laporan/file_10719000011.pdf

Istianingrum, R. (2016). Degradasi Bahasa Dayak Kenyah. Stilistika: Jurnal Pendidikan Bahasa Dan Sastra, 8(2), 87-101. http://103.114.35.30/index.php/Stilistika/article/view/107

Karyawanto, H. Y. (2018). Bentuk Lagu Dan Ambitus Nada Pada Orkestrasi Mars Unesa. Virtuoso: Jurnal Pengkajian Dan Penciptaan Musik, 1(1), 1-7. https://doi.org/10.26740/vt.v1n1.p8-14

Wulandari, P. S. (2018). "Fungsi Tari Pampaga di Desa Budaya Pampang Kalimantan Timur." Yogyakarta: ISI Yogyakarta. http://digilib.isi.ac.id/4058/

Mukhransyah, H. (2020). Khazanah Seni Tradisi Kalimantan Timur. Samarinda: Dewan Kesenian Daerah Kalimantan Timur.

Nainggolan, O. T. P. (2019). Strategi Menghafal Penjarian Tangga Nada dalam Mata Kuliah Instrumen Dasar I. Resital: Jurnal Seni Pertunjukan, 20(1), 52-59. https://journal.isi.ac.id/index.php/resital/article/view/3335

Oktadus, H. Y. (2018). Hibriditas Musikal: Strategi Budaya? Jurnal Warna, 2(2), 69-75. https://ejournal.iaiig.ac.id/index.php/warna/article/view/86

Purwaningwulan, M. M., \& Prayogo, H. (2017). Aktivitas Komunikasi Tari Kanjet Anyam Tali Suku Dayak Kenyah. Common, 1(1), 7-18. https://doi.org/10.34010/common.v1i1.244

Putri, R. R. L. (2020). Revitalisasi Tari Ajai di Desa Budaya Pampang Kecamatan Sungai Siring Kota Samarinda. http://digilib.isi.ac.id/6333/1/JURNAL.pdf

Sili, S., Hanum, I. S., \& Wahyuni, I. (2019). Etika dalam Hubungan Antar Manusia pada Beberapa Tarian Dayak Kenyah. Prosiding Seminar Nasional Bahasa, Sastra, dan Seni (Sesanti) 2019, 63-77. http://eprosiding.fibunmul.id/index.php/sesanti/article/view/8

Sitaen, H. T. (1995). Pergeseran Fungsi Musik di Tengah Kehidupan Masyarakat. Cakrawala Pendidikan, 3(3), 31-40. https://doi.org/10.21831/cp.v3i3.9189

Hadi, Y. S. (2006). Seni dalam Ritual Agama. Yogyakarta: Buku Pustaka.

Merriam, A. P. (1964). The Antropolog of Music. United States: Noorthwestern University Press.

Soedarsono, R. M. (2001). Metodologi Penelitian Seni Pertunjukan dan Seni Rupa. Bandung: Masyarakat Seni Pertunjukan Indonesia.

Departemen Pendidikan dan kebudayaan. (1995/1996). "Nilai-Nilai Budaya Di Kalimantan Timur". Kementrian Pendidikan dan kebudayaan.

Malm, W. P. (1977). Music Cultures of the Pacific, Near East, and Asia. Englewood Cliffs, New Jersey: Prentice Hall. 
Musik Iringan Hudoq Kita' sebagai Seni Pertunjukan Wisata di Desa Pampang Kota Samarinda 